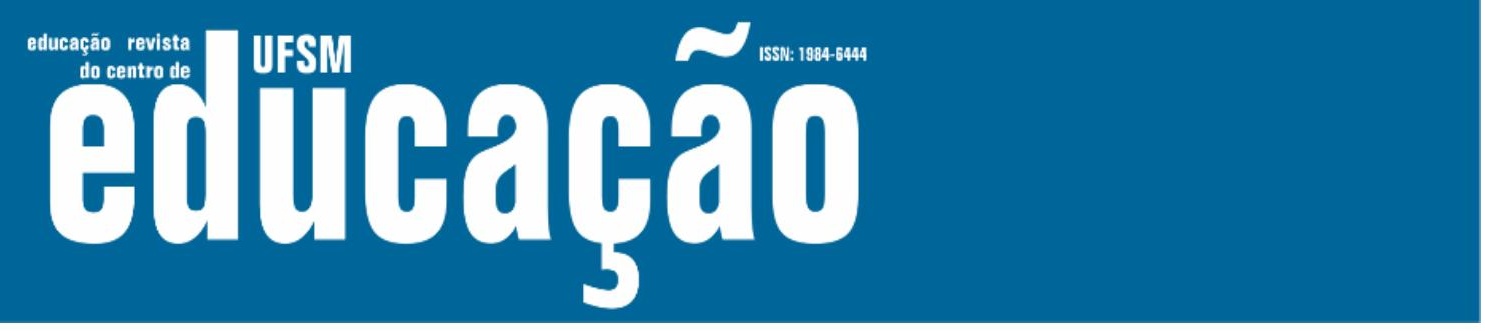

ISSN: 1984-6444 | http://dx.doi.org/10.5902/1984644444319

\title{
John Dewey: educação, democracia e coesão social'1
}

\author{
John Dewey: education, democracy and social cohesion
}

\author{
Marcus Vinicius Cunha \\ Professor Associado da Universidade de São Paulo. São Paulo, São Paulo, Brasil. \\ mvcunha2@hotmail.com - orcid.org/0000-0001-8414-7306 \\ Horacio Héctor Mercau \\ Pós-doutorando da Universidade de São Paulo. São Paulo, São Paulo, Brasil. \\ horacio.mercau@gmail.com - orcid.org/0000-0002-8854-2204
}

Recebido em 16 de maio de 2020

Aprovado em 15 de julho de 2020

Publicado em 30 de dezembro de 2021

\section{RESUMO}

Este artigo aborda as relações entre educação, democracia e coesão social, tomando por base as ideias do filósofo e educador estadunidense John Dewey. Esse tema assume especial relevância na atualidade, quando a ideia de democracia enfrenta graves desafios. O artigo discorre primeiramente sobre as propostas apresentadas por Dewey no livro Democracia e educação, publicado em 1916, sua mais importante obra educacional. O propósito dessa análise é mostrar que as teses do autor sobre educação são estreitamente vinculadas às suas teses políticas. Em seguida, são examinadas as reflexões feitas por Dewey no livro The public and its problems, publicado em 1927, desenvolvidas em confronto com as ideias do jornalista Walter Lippmann. Enquanto Lippmann defende que a democracia requer a formação de um corpo de especialistas para comandar a vida social, Dewey enfatiza a necessidade de valorizar o público, isto é, os diversos agrupamentos que compõem a sociedade e que são atingidos pela ação do estado.

Palavras-chave: John Dewey; Democracia; Coesão Social

\section{ABSTRACT}

This article addresses the relationship between education, democracy and social cohesion, based on the ideas of the American philosopher and educator John Dewey. This topic is particularly relevant today, when the idea of democracy faces serious challenges. The article first discusses the proposals presented by Dewey in the book Democracy and education, published in 1916, his most important educational work. The purpose of this analysis is to show that the author's theses on education are closely linked to his political theses. Then, the reflections made by Dewey in the book The public and its problems, published in 1927, developed in confrontation with the ideas of journalist Walter Lippmann, are examined. While Lippmann argues that 


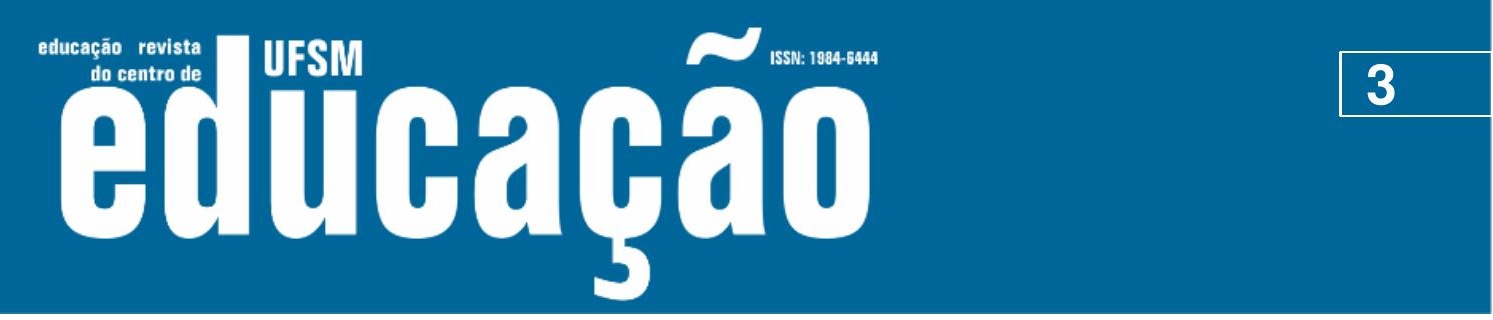

ISSN: 1984-6444 | http://dx.doi.org/10.5902/1984644444319

de 1916, seu livro mais conhecido na área de educação, é frequentemente alvo de desleituras que desconsideram ser esta a sua tese central (CUNHA, 2007). As concepções deweyanas sobre o assunto podem ser esclarecidas por meio de outras obras do autor, seja para evitar equívocos de interpretação, seja para ampliar o alcance de seu pensamento, seja ainda para auxiliar na problematização do quadro político atual. $^{2}$

Esses são os objetivos do presente artigo, no qual faremos inicialmente a explanação da ideia orientadora de Democracia e educação, destacando que o propósito de Dewey consiste em aproximar os dois polos constituintes do ofício de educar - escola e sociedade - para que se possa instituir o modo de vida democrático. Em seguida, examinaremos um de seus livros mais importantes no que tange à temática política, mais precisamente à discussão do enfraquecimento da coesão na sociedade contemporânea, The public and its problems (DEWEY, 2003c), publicado em 1927 em resposta às teses do influente jornalista Walter Lippmann (1889-1974).

\section{Escola e sociedade}

A tese central de Democracia e educação é assim enunciada por Dewey (1959b, p. 108): o "[...] objetivo da educação é habilitar os indivíduos a continuar sua educação", é "[...] propiciar a capacidade para um constante desenvolvimento" dos aprendizes, mas essa ideia "[...] só se pode aplicar a todos os membros de uma sociedade" quando se tratar de uma "[...] sociedade democrática". Esse enunciado requer a explicitação do pensamento deweyano acerca de três noções fundamentais: o que é educar; o que se entende por democracia; e como se pode realizar a educação, segundo o proposto pelo autor, em uma sociedade não democrática.

A primeira noção significa, em linhas gerais, que a educação não se esgota em conteúdos formais, ainda que permeados por conhecimentos e valores socialmente válidos e competentes para efetivar o currículo estabelecido pela escola. Só se educa verdadeiramente quando tais conteúdos são ministrados de tal forma que inspirem e habilitem o aprendiz a continuar aprendendo. Os fins da educação, portanto, não se localizam nela mesma, isto é, no que os mestres ensinam objetivamente ou no que 


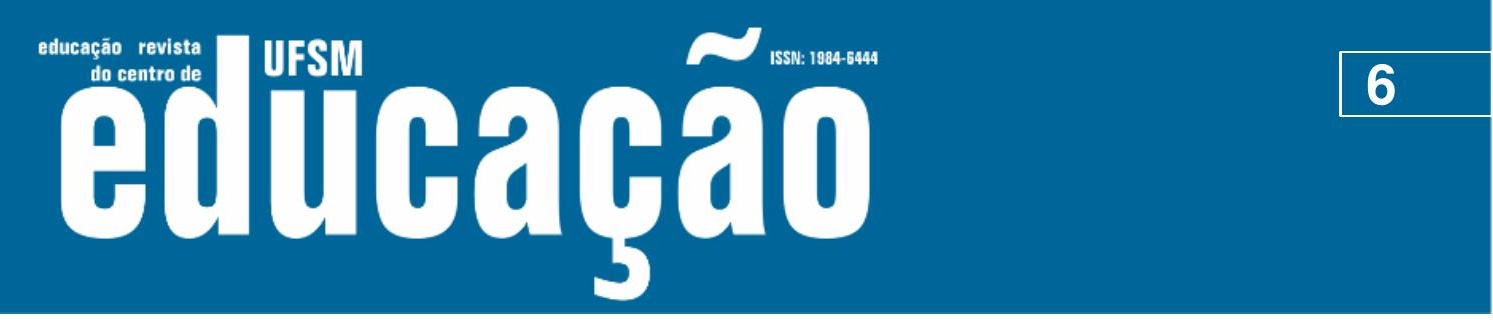

ISSN: 1984-6444 | http://dx.doi.org/10.5902/1984644444319

em Democracia e educação: "Uma democracia é mais do que uma forma de governo"; antes de tudo, é "[...] uma forma de vida associada, de experiência conjunta e mutuamente comunicada (DEWEY, 1959b, p. 93); há democracia "[...] quando a relação de um homem com outro é mútua e existem condições adequadas para a reconstrução de hábitos e instituições sociais (DEWEY, 1959b, p. 108).

Em suma, a definição deweyana de democracia não desconsidera a forma assumida pelas instituições sociais, mas privilegia o modo como os integrantes dos diversos agrupamentos interagem entre si. É nesse ponto que se visualiza o tema da coesão social em Dewey: para que haja democracia, é preciso que os indivíduos e os grupos se posicionem como participantes de uma experiência comum; as suas diferentes - e mesmo divergentes - visões de mundo precisam ser compartilhadas; todos os envolvidos devem se manter dispostos a agir com vistas a transformar continuamente o que se estabeleceu como certo. A experiência democrática é feita por condutas individuais e coletivas avessas a concepções dogmáticas.

Seria contraditório se Dewey fizesse uma descrição pormenorizada do funcionamento de uma sociedade democrática, pois o seu propósito é sugerir princípios gerais a serem ajustados em respeito às características de cada situação específica. Sua definição de democracia é necessariamente sucinta, mas o mesmo não se observa na discussão acerca das razões por que não temos e nunca tivemos uma democracia e, consequentemente, por que não temos e nunca tivemos uma experiência escolar democrática - nos termos por ele definidos.

Toda a terceira parte de Democracia e educação - os capítulos 18 ao 23 - é dedicada a esse tema. Ao término do livro, Dewey (1959b, p. 355) conclui sua análise dizendo que o fracasso da democracia decorre do modo segregado como se comportam os agrupamentos sociais, cada qual com seus interesses exclusivistas, "[...] tendo cada qual seu valor, seu material e seu método independentes e próprios, em colisão uns com os outros". As causas mais profundas desse fenômeno estão nas "[...] divisões da sociedade em classes e grupos mais ou menos rigidamente demarcados", o que configura o enfraquecimento da coesão social e, consequentemente, da própria democracia. 


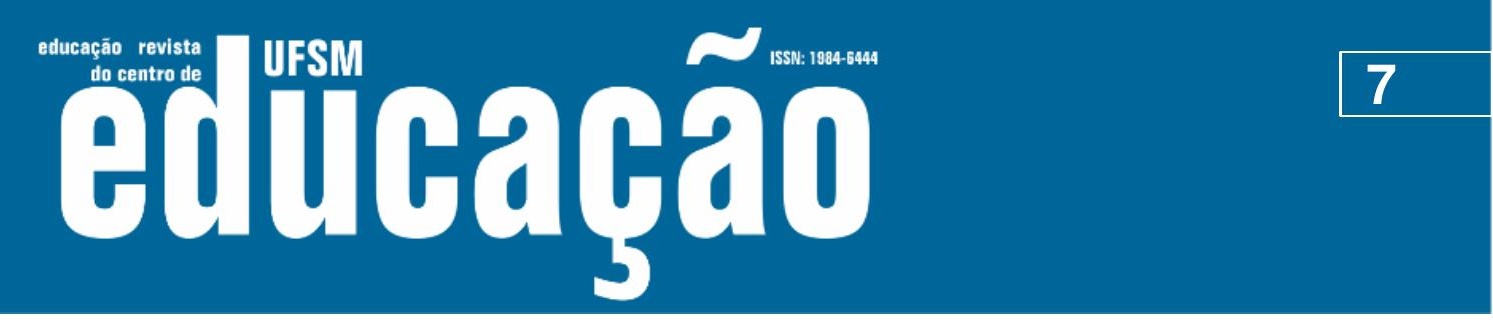

ISSN: 1984-6444 | http://dx.doi.org/10.5902/1984644444319

A história de nossa civilização é marcada por essa configuração social, cuja origem Dewey identifica na Grécia Clássica, berço da democracia, com reflexos imediatos na educação. A separação entre "[...] educação liberal" - a instrução que não conduz ao trabalho, mas aos conteúdos mais requintados da cultura - e "[...] educação profissional e industrial", como se vê na atualidade, descende

[...] da divisão entre a classe dos que precisavam trabalhar para viver e a dos que se achavam forros dessa necessidade. A ideia de que a educação liberal dada aos homens da última classe é intrinsecamente mais elevada do que o adestramento servil da primeira reflete a circunstância de socialmente ser uma dessas classes livre, e a outra escravizada (DEWEY, 1959b, p. 275-276)

Inúmeras outras configurações foram experimentadas desde então, mas a essência do problema permanece: a divisão da sociedade em classes, a separação entre os que trabalham e os que usufruem do trabalho alheio. As consequências dessa polarização que remonta à nossa origem civilizatória vão além do dualismo educacional, abrangendo outros setores, como as ciências e as artes. Em "Liberalismo e ação social", de 1935, Dewey (1970, p. 76) afirma que

A aplicação da ciência e mesmo a sua própria expansão foram condicionadas em grau considerável pelo sistema a que se deu o nome de capitalismo, designação que cobre um complexo de arranjos políticos e jurídicos centralizados em um modo particular de relações econômicas. Devido a terem ficado a ciência e a tecnologia condicionadas por esse complexo, a segunda e humanamente mais importante parte da predição de Bacon em grande parte não se realizou. A conquista das forças naturais não trouxe, de nenhum modo, o melhoramento da situação do homem, no grau previsto por ele.

Em Arte como experiência, de 1934, Dewey (2010, p. 577) analisa o processo de coisificação instituído pela sociedade de classes, dizendo: "Enquanto a arte for o salão de beleza da civilização, nem a arte nem a civilização estarão seguras". O atual empobrecimento da experiência estética terá continuidade "[...] enquanto a massa de homens e mulheres que faz o trabalho útil do mundo não tiver a oportunidade de ficar livre para conduzir os processos de produção, e não for ricamente dotada da possibilidade de gozar dos frutos do trabalho coletivo" (DEWEY, 2010, p. 578).

É notório o descontentamento de Dewey com o capitalismo, cujos efeitos atingem negativamente a educação e demais setores da cultura, produzindo um 


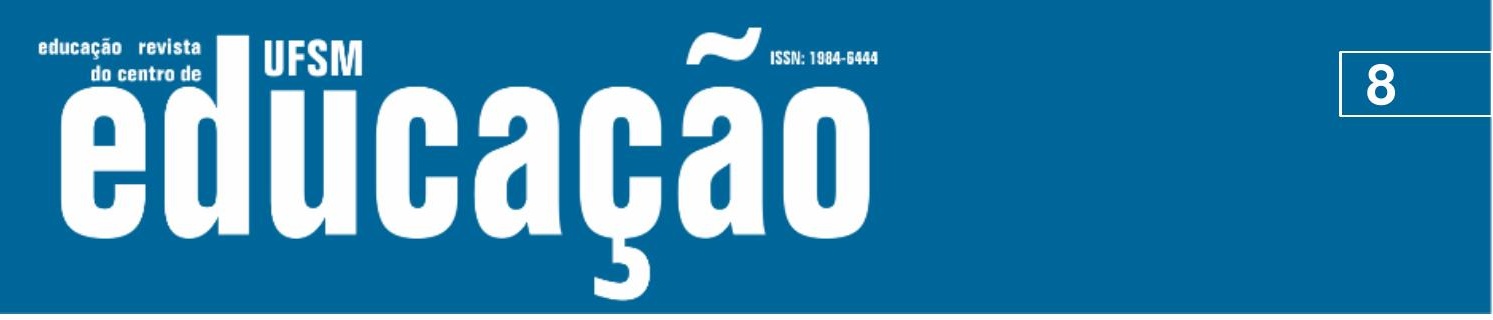

ISSN: 1984-6444 | http://dx.doi.org/10.5902/1984644444319

ambiente que em nada se aproxima do modo de vida democrático por ele almejado. Ao colocar no cerne do problema a histórica divisão da sociedade em classes e a desigualdade no âmbito do trabalho, suas críticas se assemelham às que derivam do marxismo.

\begin{abstract}
O problema do trabalho e do emprego, do qual temos tão aguda consciência, não pode ser solucionado por meras alterações no salário, na jornada de trabalho e nas condições sanitárias. Nenhuma solução permanente é possível senão em uma alteração social radical, que afete o grau e o tipo de participação do trabalhador na produção e na administração social dos bens que ele produz. (...) A ideia de que o problema fundamental pode ser resolvido pelo simples aumento das horas de lazer é absurda. Tal ideia meramente preserva a antiga divisão dualista entre trabalho e lazer. (DEWEY, 2010, p. 575-576)
\end{abstract}

Dewey tinha familiaridade com a União Soviética, onde esteve no final da década de 1920 e de onde trouxe impressões bastante positivas, as quais, aliás, o tornaram alvo de inúmeras críticas nos Estados Unidos (BRICKMAN, 1971). Mas a saída por ele proposta para enfrentar o cenário desumanizador instaurado pelo capitalismo, diverge da via marxista.

Em "Liberalismo e ação social”, Dewey (1970, p. 78-79) assim descreve a proposição central de Marx (1818-1883):

A luta de classes, como uma guerra civil, irromperá afinal em revolução aberta, cujo resultado será ou a ruína comum das partes em conflito, ou a reconstituição revolucionária da sociedade em geral pela transferência do poder de uma classe a outra.

Sua divergência incide no método comunista para alcançar a "[...] mudança social radical": "A insistência em que o uso de força violenta é inevitável limita o uso da inteligência disponível, pois onde reina o inevitável, a inteligência não pode ser usada. Compromisso com a inevitabilidade é sempre um resultado de dogma", o que, como vimos acima, opõe-se diretamente ao modo de vida democrático.

Sua crítica não é dirigida ao que Marx propôs no século XIX, tendo por base a "[...] observação das condições existentes" em sua época. A discordância reside no caráter de universalidade e inevitabilidade da solução por ele apresentada, pois toda generalização deve ser sempre reavaliada mediante constante exame dos fatos, "[...] continuada observação das condições existentes, testando-se e revendo-se todas as 


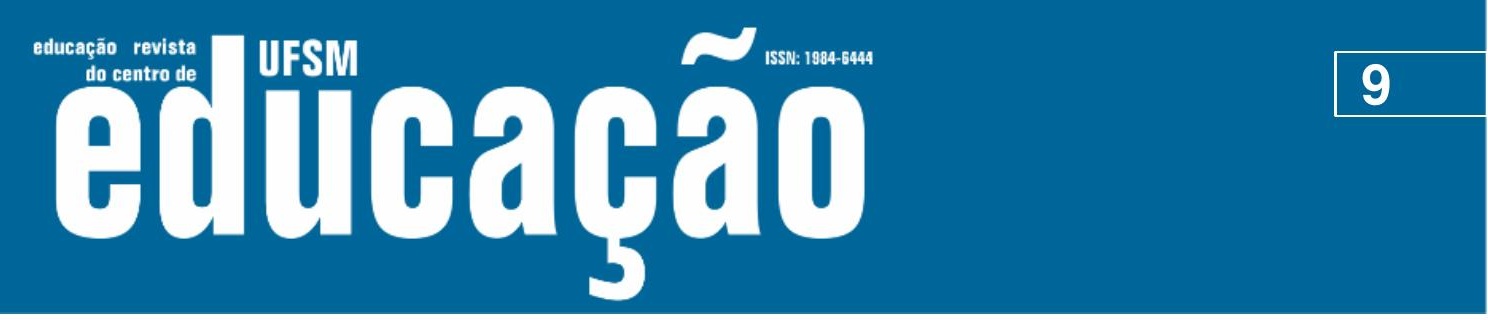

ISSN: 1984-6444 | http://dx.doi.org/10.5902/1984644444319

primeiras generalizações na base do que for agora observado".

A fraqueza teórica do marxismo está em ter-se suposto que uma generalização feita em uma data e lugar particular (...) pode tornar dispensável a necessidade de recorrer-se continuamente à observação e à revisão das generalizações na sua função de hipóteses de trabalho. Em nome da ciência, formulou-se um procedimento completamente anticientífico, de acordo com o qual se fez uma generalização, que se passou a considerar como uma "verdade" final e, portanto, válida em todos os tempos e lugares. (DEWEY, 1970, p. 177-178)

Quando esse juízo foi publicado, Dewey já não se expressava positivamente acerca da União Soviética, então mergulhada na era stalinista. O que o havia impressionado favoravelmente em sua visita ao país, fora a disposição do estado em promover iniciativas de cooperação e civismo entre os cidadãos, com notáveis reflexos nas práticas escolares. Os novos direcionamentos da vida política e social lá instituídos, no entanto, o fizeram rever suas conclusões e enfatizar a necessidade de meios alternativos para obter a pretendida transformação radical da sociedade (BRICKMAN, 1971; OLIVEIRA, 2018). Em vez da guerra aberta entre as classes para a instauração da ditadura do proletariado, Dewey $(1970$, p. 80) prefere o "[...] método da democracia", pelo qual os conflitos são levados ao espaço público, "[...] onde em aberto ser vistos e avaliados, onde podem ser discutidos e julgados à luz de interesses mais amplos do que os representados por cada uma das partes separadamente".

Em suma, contrariamente à inevitabilidade dogmática que sustenta um rumo certo para a história - dois rumos possíveis, na verdade: ou a revolução ou a barbárie -, Dewey (1970, p. 80) opta por uma atitude "[...] experimentalista", concepção que remete à ideia de investigação, tal qual vimos acima: fazer da democracia um problema a ser abordado por meio da experiência reflexiva; ver a sociedade democrática como uma proposição que gera perplexidade e dúvida, cujo caráter é indeterminado; entender a democracia como um processo contínuo cuja realização é educativa porque o seu valor reside não na obtenção de um formato institucional definitivo, mas na transformação que ocasiona nos sujeitos que o vivenciam. A coesão social, critério fundante do modo de vida democrático, não é o resultado final da investigação, mas uma decorrência possível dessa busca. 


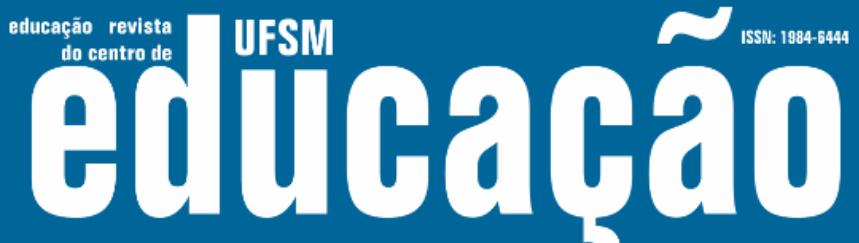

ISSN: 1984-6444 | http://dx.doi.org/10.5902/1984644444319

A terceira indagação enunciada no início da presente seção - como realizar em uma sociedade não democrática a educação proposta por Dewey - pode ser respondida à luz dessa definição dinâmica de democracia, inspirada no conceito deweyano de pensamento reflexivo. A democracia não é um modo de vida existente, mas um fim que almejamos e que nada nos garante alcançar; democracia é um problema a ser enfrentado experimentalmente, não um conjunto de instituições definitivamente estabelecidas; a investigação em prol da democracia é, em si mesma, uma experiência educativa, independentemente do volume de vitórias alcançadas. Se concordarmos com esses termos, concordaremos também que a resposta à indagação consiste em praticar a educação democrática em todos os espaços disponíveis, mesmo de maneira imperfeita e limitada, sempre em busca de intercâmbios capazes de humanizar a vida.

\section{Desafios à democracia}

A ênfase de Dewey na necessidade de analisar as condições existentes examinar continuadamente os fatos para não incorrer em generalizações e dogmatismos - revela sua disposição para investigar a realidade de seu tempo. Essa disposição se evidenciou na década de 1920 com a publicação de The public and its problems (DEWEY, 2003c), obra que dialoga criticamente com Public opinion, de Walter Lippmann (1998). Os dois trabalhos fazem parte do episódio que ficou conhecido como 'debate Lippmann-Dewey', oferecendo significativa contribuição para o amadurecimento da noção de democracia na sociedade norte-americana, considerando as peculiaridades do avanço do capitalismo em todo o mundo ocidental.

Tanto um livro quanto outro, ocupam-se do problema da coesão social, sendo que a obra de Lippmann (1998), publicada em 1922, tem por base a necessidade de levar em conta o ambiente real, as características próprias da vida no país, concluindo que as pessoas não têm habilidade para conhecer esse ambiente em toda a sua complexidade, variedade e combinações. Seu propósito é favorecer o bom funcionamento da democracia, mas não acredita que o interesse público seja alcançado e mantido por uma população submetida às regras do mercado de trabalho 


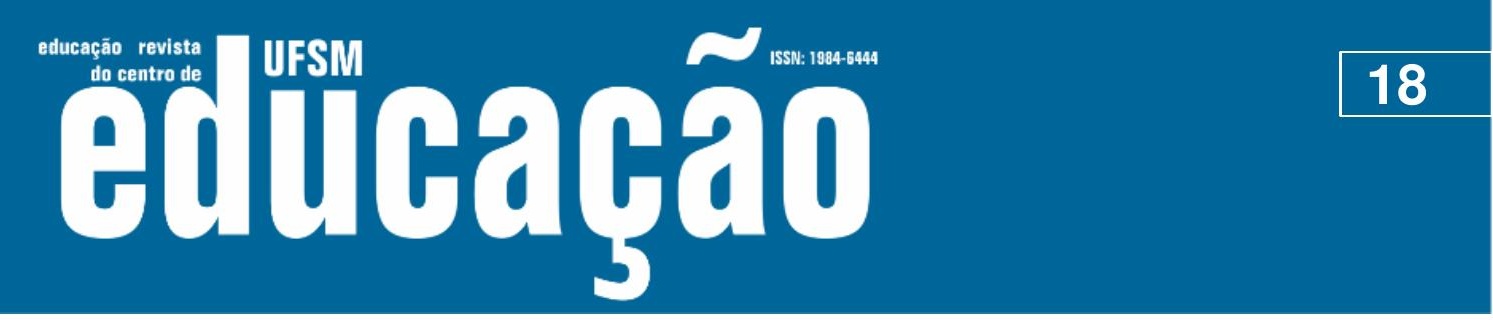

ISSN: 1984-6444 | http://dx.doi.org/10.5902/1984644444319

abordagens teóricas e iniciativas práticas que, marcadas pela ousadia, dinamizem a relação entre professores e alunos, envolvendo as instituições de ensino. Podemos pensar em novas concepções pedagógicas inspiradas na ideia deweyana de publicity: relações educativas baseadas na liberdade de expressão e discussão, que promovam a troca de ideias e a confiança mútua entre os participantes e fortaleçam a capacidade de ouvir e aprender com o outro. A ideia de publicity é consumada na proposta que Dewey elaborou em suas obras educacionais: uma educação voltada prioritariamente para desenvolver o pensamento reflexivo, a investigação social livre capaz de abranger todo o potencial criativo de mestres e educandos, sua imaginação e sensibilidade, e criar hábitos de inteligência unidos à esperança de que é possível transformar radicalmente a vida em sociedade.

\section{Referências}

AMARAL, Maria N. Camargo Pacheco. Dewey: filosofia e experiência democrática. São Paulo: Perspectiva, Edusp, 1990.

BERNSTEIN, Richard J. Filosofía y democracia: John Dewey. Herder: Barcelona, 2010.

BRICKMAN, William W. Actitudes del Estado Soviético hacia John Dewey considerado como educador. In: LAWSON, Douglas E.; LEAN, Arthur E. (Orgs.). John Dewey: visión e influencia de um pedagogo. Buenos Aires: Nova, 1971, p. 99-210.

COX, Cristian. Expansión del acceso y reformas del currículo en la educacion escolar Latinoamericana: implicancias para la cohesion social. In: BRUNO-JOFRÉ, Rosa; JOVER, Gonzalo (Orgs.). Encounters on education, v. 9. Madrid: Universidad Complutense de Madrid, 2008.

CUNHA, Marcus Vinicius. Leituras e desleituras da obra de John Dewey. In: BENCOSTA, Marcus Levy A. (Org.). Culturas escolares, saberes e práticas educativas: itinerários históricos. São Paulo: Cortez, 2007. p. 357-378.

DEWEY, John. Como pensamos: como se relaciona o pensamento reflexivo com o processo educativo - uma reexposição. 3. edição. Tradução de Haydée de Camargo Campos. São Paulo: Nacional, 1959a.

DEWEY, John. Democracia e educação: introdução à filosofia da educação. Tradução de Godofredo Rangel e Anísio Teixeira. 3. edição. São Paulo: Nacional, 1959b. 


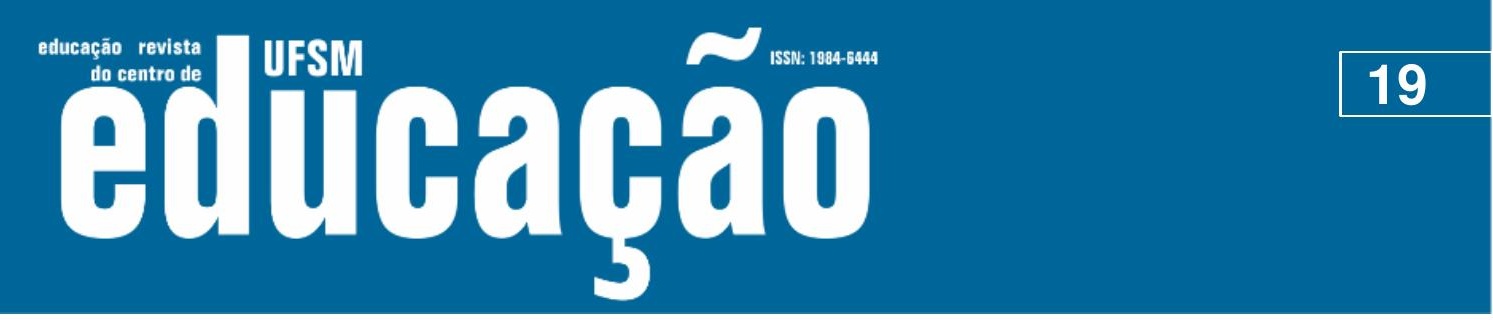

ISSN: 1984-6444 | http://dx.doi.org/10.5902/1984644444319

DEWEY, John. Liberalismo e ação social. In: DEWEY, John. Liberalismo, liberdade e cultura. Tradução de Anísio Teixeira. São Paulo: Nacional, EDUSP, 1970.

DEWEY, John. Experiência e educação. Tradução de Anísio Teixeira. São Paulo: Nacional, 1971.

DEWEY, John. Freedom and culture. In: BOYDSTON, Jo Ann; HICKMAN, Larry (Orgs.). The collected works of John Dewey, 1882-1953. The Later Works, 1925-1953. v. 13: 1938-1939. Electronic Edition, 2003a, p. 66-189.

DEWEY, John. Practical democracy. In: BOYDSTON, Jo Ann; HICKMAN, Larry (Orgs.). The collected works of John Dewey, 1882-1953. The Later Works, 1925-1953. v. 2: 1925-1927. Electronic Edition, 2003b, p. 214-221.

DEWEY, John. The public and its problems: an essay in political inquiry. In: BOYDSTON, Jo Ann; HICKMAN, Larry (Orgs.). The Collected Works of John Dewey, 1882-1953. The Later Works of John Dewey, v. 2: 1925-1927. Electronic Edition, 2003c.

DEWEY, John. Public opinion. In: BOYDSTON, Jo Ann; HICKMAN, Larry (Orgs.). The collected works of John Dewey, 1882-1953. The Middle Works of John Dewey, 18991924. v. 13: 1921-1922. Electronic Edition, 2003d, p. 338-345.

DEWEY, John. Arte como experiência. Tradução de Vera Ribeiro. São Paulo: Martins Fontes, 2010.

GARRISON, Jim (Org.). Reconstructing democracy, recontextualizing Dewey. Albany: State University of New York, 2008.

LIPPMANN, Walter. Public opinion. New Jersey: Transaction Publishers, 1998.

LIPPMANN, Walter. The phantom public. New York: Harcourt, Brace and Co., 1925.

MOREIRA, Carlos O. Fiúza. Entre o indivíduo e a sociedade: um estudo da filosofia da educação de John Dewey. Bragança Paulista: EDUSF, 2002.

SORJ, Bernardo; MARTUCCELLI, Danilo. El desafío latinoamericano: cohesión social y democracia. Buenos Aires: Siglo XXI, 2008.

OLIVEIRA, Marco Antônio G. As impressões de John Dewey sobre a escola russa soviética em 1928: a importância da dimensão política e social da educação para constituição de uma sociedade democrática. 2018. 208f. Tese (Doutorado em Educação) - Universidade Federal de Uberlândia, Uberlândia.

PAPPAS, Gregory Fernando. John Dewey's ethics: democracy as experience. Bloomington: Indiana University, 2008. 


\section{uss \\ 1SSN: $1984-6444$

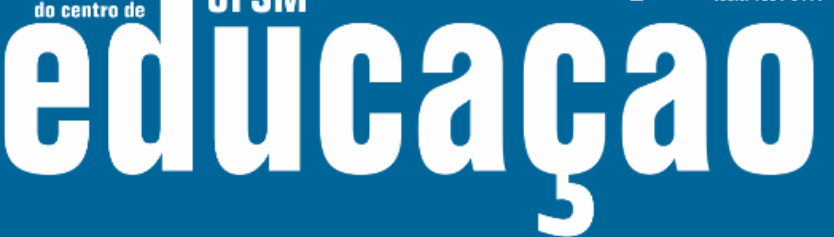

ISSN: 1984-6444 | http://dx.doi.org/10.5902/1984644444319

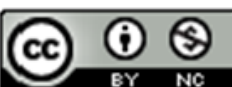

This work is licensed under a Creative Commons Attribution-NonCommercial 4.0 International (CC BY-NC 4.0)

\section{Notas}

1 As pesquisas que originaram este artigo foram subvencionadas pelo Conselho Nacional de Desenvolvimento Científico e Tecnológico (CNPq, Brasil) e pela Coordenação de Aperfeiçoamento de Pessoal de Nível Superior - Brasil (CAPES) - Código de Financiamento 001.

2 Vários analistas reconhecem que as concepções educacionais deweyanas são eminentemente políticas. Ver, por exemplo, Amaral (1990), Moreira (2002), Bernstein (2010), Pappas (2008) e Garrison (2008). 